\title{
Qualidade de Vida de Cuidadores e Pacientes com Diagnóstico de Esclerose Lateral Amiotrófica - Editorial
}

\section{Adriana Teresa Silva}

Fisioterapeuta, Especialista em Fisioterapia neurofuncional, mestranda em Ciências Médicas do departamento de Neurologia da UNICAMP, Campinas-SP, Brasil.

Qualidade de vida é um termo de difícil conceitualização, mas existe razoável concordância entre os pesquisadores do grupo de estudo sobre a qualidade de vida da Organização Mundial da saúde, que define sendo a "percepção do indivíduo de sua posição na vida, no contexto da cultura e sistemas de valores nos quais vive e em relação aos seus objetivos, expectativas, padróes e preocupaçôes”. Nessa conceitualização incluem seis domínios principais: saúde física, estado psicológico, nívies de independência, relacionamento social, características ambientais e padrão espiritual ${ }^{1}$.

Quando um membro da família adoece, interfere na rotina do sistema familiar gerando estresse, aumentos de custos, inseguranças e culpas. O diagnóstico de uma doença fatal gera manifestações emocionais nos pacientes tais como: depressão, tristeza, ódio, dor da separação os quais possibilitam uma maior fragilidade e apego familiar. Doenças crônicas demandam de maiores cuidados, mais gastos e uma exaustão por algum membro da família, afetando a sua qualidade de vida ${ }^{2,3}$.

A Esclerose Lateral Amiotrófica (ELA) é uma das maiores doenças neurodegenerativas. Seu diagnóstico é devastador e carretado de fatalismo. ELA é caracterizada por doença do neurônio motor - envolve a degeneração do sistema motor em todos os níveis (à partir do córtex ao corno anterior da medula espinhal). $\mathrm{O}$ sinais físicos deste transtorno, abrange tanto neurônio motor superior e inferior. A queixa inicial é a fraqueza muscular focal tendendo a se generalizar simetricamente, que ao exame físico revela-se como amiotrofia, redução de força muscular e miofasciculaçóes. $\mathrm{O}$ tônus muscular pode estar aumentado ou diminuído de acordo com a fase evolutiva, acompanhado de aumento ou diminuição dos refle- xos profundos. $\mathrm{O}$ comprometimento bulbar manifestase normalmente como uma disartria ou disfagia. Nessa doença não há compromentimento primário das funçôes sensitivas, vesico-esfincterianas e sexuais como também das funçóes corticais superiores. $\mathrm{O}$ curso desta doença é inexoravelmente progressivo, com $50 \%$ dos pacientes morrendo dentro de 3 anos de iníció.

Com o passar dos anos os pacientes acometido pela doença, exibem um declínio das capacidades funcionais que inicia nos membros superiores e progride para os membros inferiores, tronco e musculatura respiratória levando a insuficiência respiratória, sendo a principal causa de morte neste pacientes 5 .

A perda da capacidade funcional leva o indivíduo a incapacidade para realizar atividades de vida diária: comer, vestir, caminhar, tomar banho sozinho, caminhar em casa, virar na cama e transferência. Da mesma forma das atividades instrumentais tais como: fazer compras, limpar casa, dirigir, lavar roupas e utilizar meios de transportes públicos. Acarreta ao indivíduo a dependência de um cuidador para tais atividades ${ }^{6}$.

Assim para que haja um entendimento melhor das variáveis que podem influenciar na qualidade de vida dos cuidadores com ELA na edição da Revista Neurociências volume 20, número 02 o estudo de Orsini et al., mensura a qualidade de vida dos cuidadores de pacientes com $\mathrm{ELA}^{7}$. Ao analisar nove cuidadores, evidenciaram que os domínios aspectos emocionais, sociais, vitalidade e saúde mental são os quesitos mais acometido pelos cuidadores ao longo do curso desta doença. O estudo destes autores, mostra ser relevante a comunidade científica, no que diz respeito a qualidade de vida dos cuidadores, necessitando uma maior atenção a estas pessoas. 


\section{REFERÊNCIAS}

1.Fleck MPA, Louzada S, Xavier M, Chachamovich E, Vieira G, Santos L, et al. Aplicação da versão em português do instrumento abreviado de avaliação da qualidade de vida "WHOQOL-bref”. Rev Saúde Pública 2000;34:178-83. http://dx.doi.org/10.1590/S0034-89102000000200012

2.Torres WC. As perdas do paciente terminal: o luto antecipado. Psicol Argum 2001;19:7-12.

3.Marcon SS, Sassá AH, Soares NTI, Molina RCM. Dificuldades e conflitos enfrentados pela família no cuidado cotidiano a uma criança com doença crônica. Cienc Cuid Saude 2007;6:411-9.

4.Mitchell JD, Borasio GD. Amyothophic lateral Sclerosis. Lancet 2007;369:2031-41
http://dx.doi.org/10.1016/S0140-6736(07)60944-1

5.Lee EC, Annegers JF, Appel SH. Prognosis of amyotrophic lateral sclerosis and the effect of referral selection. J Neurol Sci 1995;132:207-15.

http://dx.doi.org/10.1016/0022-510X(95)00154-T

6.Costa EC, Nakatani AYK, Bachion MM. Capacidade de idoso da comunidade para desenvolver atividade de vida diária e atividade instrumentais de vida diária. Acta Paul Enferm 2006;19:43-8.

http://dx.doi.org/10.1590/S0103-21002006000100007

7.Orsini M, Mello M, Lisieux D, Pássaro CP, Leite MAA, Baldez AC, Silva JG, Menezes SLS, Porto FH, Machado D, Bastos VH, de Freitas MRG, Oliveira AB. Qualidade de Vida de Cuidadores e Pacientes com Diagnóstico de Esclerose Lateral Amiotrófica. Rev Neurocienc 2012;20(2):215-21. 